УДК 82I.I33.I.09

ББК $83.3(4 Ф$ ра $) 5 \mathrm{I}$
ОРЛЕАНСКИЙ ЭПИЗОД В «МЕМУАРАХ» МАДЕМУАЗЕЛЬ ДЕ МОНПАНСЬЕ И ИДЕАЛ ГЕРОИЧЕСКОГО ФЕМИНИЗМА

DOI: IO.22455/2500-4247-20I7-2-2-40-55

Аннотация: В статье рассматривается влияние идеала герочческого феминизма на конструирование автобиографического образа в орлеанском эпизоде «Мемуаров» Мадемуазель де Монпансье (г627-I693). Значимость этого эпизода определяется его связью с главным городом наследственных владений семьи мемуаристки. Подтвердив свою власть в Орлеане в период Фронды принцев, она стремилась продемонстрировать силу знатных родов как единственной настоящей опоры короля и свои оппозиционные настроения по отношению к кардиналу Мазарини. Действия протагонистки в городе анализируются сквозь призму сложившихся представлений о главной французской защитнице национальных интересов Жанне д’Арк, отразившихся в исторических источниках, драматургии (Вернуль, д’биньяк и др.) и прозе (Бероальд де Вервиль). В орлеанском эпизоде важными оказываются два значения, входивших в смысловой ореол образа Девы к середине XVII в.: героического служения Франции и божественного чуда, явленного в ее деяниях. Имя Жанны д’Арк вписывается в более широкий культурный контекст и связывается с идеей герочческого феминизма, восходящей к образу античной богини Афины и отраженной в судьбах исторически реальных «femmes fortes», а также в литературных образах воительниц-амазонок из поэм итальянских гуманистов (Ариосто, Тассо) и героинь Корнеля. Сопоставление протагонистки с этими образами показывает, что атмосфера придворной и салонной культуры эпохи, насыщенная примерами возвышенно-героических поступков необыкновенных женщин, повлияла на конструирование автобиографического «я» и помогла мемуаристке описать восшествие в Орлеан как триумфальный эпизод своей жизни, отвечавший ее возвышенным представлениям о собственном предназначении. Мадемуазель показала себя отважной принцессой, достойной славы Бурбонов, ведомой Провидением и поддерживаемой народом.

Ключевые слова: мемуары, французская литература XVII в., Мадемуазель де Монпансье, героический феминизм, «femmes fortes», Жанна д’Арк, Ариосто, Тассо, Корнель.

Информация об авторе: Светлана Юрьевна Павлова - кандидат филологических наук, доцент, Саратовский национальный исследовательский государственный университет им. Н.Г. Чернышевского, ул. Астраханская, д. 83, 4IоOІ2 Саратов, Россия.

E-mail: pavlovasy@info.sgu.ru 


\section{THE ORLEANS EPISODE OF MADEMOISELLE DE MONTPENSIER'S MEMOIRS AND THE IDEAL OF HEROIC}

This is an open access article distributed under the Creative Commons Attribution 4.0 International (CC BY 4.0)

\section{FEMINISM}

(C) 20I7. S.Yu. Pavlova

N.G. Tchernyshevsky National Research Saratov State

University,

Saratov, Russia

Received: December 20, 2016

Date of publication: June 25, 2017

Abstract: The paper examines the influence of heroic feminism on the construction of the autobiographical subject in the Memoirs by Mademoiselle de Montpensier (I627-I693), specifically in its Orleans episode. This episode is important as takes place in the central city of the author's hereditary estate. During the Fronde des Nobles, haven confirmed her power over the city of Orleans, Mademoiselle tried to demonstrate that the nobles were the King's true support and that she was in opposition to Cardinal Mazarin. The article analyzes the way the narrator's actions in the city are described in the Memoirs in the light of the concept of Jeanne d'Arc as the greatest champion of French national interest, promoted in historiography, drama (Vernulz, d'Aubignac etc.), and fiction (Beroalde de Verville). Two aspects of Jeanne's image, established by the mid- $I 7^{\text {th }}$ century, become most important in the Orleans episode of the Memoirs: her heroic service to France and God's miracle manifested in her deeds. Jeanne d'Arc thus becomes part of a wider cultural context related to the tradition of heroic feminism that may be traced back to the Ancient Greek goddess Athena and manifests itself most fully in the image of "femmes fortes," both historical and fictional (cf.: amazons in Ariosto, Tasso or Corneille's female characters). The comparison of the narrator of the Memoirs with these images demonstrates that a peculiar ambience of the court and salon culture of the period that was apt to glorify exceptional heroic women enabled the memoirist to describe her entry to Orleans as triumphant episode of her life and in accordance with sublime understanding of her higher mission. Mademoiselle pictures herself as a courageous Princess worthy of Bourbon's fame guided by Providence and loved by the people.

Keywords: memoirs, $\mathrm{I} 7^{\text {th }}$ century French Literature, Mademoiselle de Montpensier, heroic feminism, "femmes fortes," Jeanne d'Arc, Ariosto, Tasso, Corneille.

Information about author: Svetlana Yu. Pavlova, PhD in Philology, Associate Professor, N.G. Tchernyshevsky National Research Saratov State University, Astrakhanskaya, 83, 4IOOI2 Saratov, Russia.

E-mail: pavlovasy@info.sgu.ru 
Мемуары Мадемуазель де Монпансье (1627-1693), старшей дочери Гастона Орлеанского, принадлежат к числу наиболее примечательных образцов французской мемуарной прозы второй половины XVII в. Они дают представление об удивительной жизни кузины Людовика XIV, а также о способах конструирования образа «Я» в автобиографической литературе эпохи. Одним из важных эпизодов биографии Мадемуазель, получившим подробное отражение в ее мемуарах (публ. І7І7 г.), стал въезд в Орлеан в период Фронды принцев.

Этот город являлся важнейшей частью наследственных владений герцогов Орлеанских. Его история еще со времен Столетней войны была тесно связана с именем Жанны д’Арк, самой знаменитой французской воительницы и защитницы национальных интересов, что не могло не оказать влияния на самосознание Мадемуазель, особенно в период пребывания в Орлеане. Для французов судьба Жанны д’Арк (I4I2-I43I) - это свидетельство воли Провидения, героической жизни во имя спасения отечества и короны, мученической смерти и святости. «Личность этой героини по праву считается одним из главных “мест памяти” французской истории» [II, c. I]. Ее культ сформировался уже в XV в. и был особенно силен в Орлеане, где с 8 мая I429 г., дня снятия английской осады французской армией под предводительством Жанны, ежегодно отмечался праздник ее имени, в том числе с разыгрыванием популярной «Мистерии об осаде Орлеана», ставшей первым сценическим воплощением ее образа. В этом городе в 1472 г. впервые прозвучал призыв о приобщении Орлеанской Девы к лику святых, а в XVII в. возник прецедент ее локальной канонизации (об этих фактах см.: [II, с. II, 32; 8, с. I88, I9I-I92]). С момента сожжения на костре по 
обвинению в ереси представления о Жанне д’Арк претерпели существенную трансформацию, начиная с реабилитации в I456 г. и вплоть до официальной канонизации в г920 г.

Одним из значимых этапов в создании ее легенды стал XVII в. Как показала О.И. Тогоева, в исторических сочинениях, жизнеописаниях и эпистолярии этого периода происходит наметившееся еще в предшествующем столетии усиление героического начала в образе Девы. Оно стало следствием влияния гуманистической традиции итальянского Возрождения, опиравшейся на античные примеры (богиня Афина, амазонка Пентесилея) (см. об этом подробнее: [II, c. 30]). Эту тенденцию отражали и театральные постановки. Она обозначилась уже в первой авторской пьесе Фронтона дю Дюка «Трагическая история о деве из Домреми» (1580), но еще ярче проявилась в следующем по времени произведении - «Трагедии о Жанне д’Арк по прозванию Орлеанская дева», опубликованной в г6оо г. и приписываемой Жану де Вире, сеньору де Гравье. Анализируя особенности сценического воплощения образа Девы в драматургии раннего Нового времени, И.А. Некрасова указывает, что в этой пьесе «поражает изобилие античных образов», проявляющееся в том числе и в самооценке главной героини [9, c. 302]. Наряду с героизацией, с началом «католического Возрождения» наблюдается еще одна важная тенденция в восприятии Жанны: открытое стремление французов провозгласить ее святой. Такой агиографический поворот присутствовал в историографии, а также в театральных постановках, где Орлеанская Дева предстала как «персонаж религиозной трагедии при этом трагедии национальной и исторической», позволявшей возвысить героиню и подчеркнуть факт ее «избранности - историей и Богом» [9, c. 298]. Особую роль в процессе сакрализации образа Жанны д’Арк сыграл кардинал Ришелье, «чье желание превратить Деву в идеальную героиню эпохи абсолютизма привело к созданию по его личному заказу сочинений Н. Вернуля, Ф. д’Обиньяка и Ж. Шаплена» [ІІ, с. Іо-ІІІ].

Из упомянутых литературных произведений самый заметный след в формировании общенациональной легенды о святой Жанне оставила героическая поэма Жана Шаплена «Девственница, или Освобожденная Франция» (І656). Она была опубликована после того, как в I653 г. герцогиня де Монпансье описала орлеанский эпизод, и может быть показательна лишь в плане общего восприятия образа Девы. Впрочем, временной ори- 
ентир не может служить единственным критерием вероятности влияния на мемуаристку того или иного сочинения. Помимо года публикации следует учитывать направленность, доступность и языковую форму произведений, которые могли повлиять на Мадемуазель. Так, ей вряд ли была известна пьеса иезуита Николя Вернуля “Iоanna Darcia” (г629), поскольку она представляла собой образец латинской ученой трагедии. Проблематична вероятность ее знакомства и с творением Франсуа Эделена д’обиньяка «Орлеанская дева. Трагедия в прозе сообразно исторической истине и требованиям театра» (I642), поскольку введение в сюжетную канву мотива земной любви Жанны привело к тому, что «пьеса не только не имела успеха, но и спровоцировала скандал» [8, с. г89].

Среди литературных сочинений, посвященных Жанне д’Арк, особое место занимает роман Бероальда де Вервиля «Орлеанская девственница» (І599), свидетельствующий о том, что в раннее Новое время образ Девы вдохновлял не только драматургов, но и прозаиков. Роман значится в «Золотой книге Жанны д’Арк» (I894) - библиографическом своде ссылок на произведения, связанные с именем воительницы. Автор библиографии, критикуя художественные достоинства «Орлеанской девственницы», тем не менее, отмечает ее отличительные особенности: «<... это настоящий рыцарский роман, смешивающий стихи и любовные эпизоды во вкусе конца XVI в. с приятными сценами, рассказанными галантным, манерным и цветистым языком» [I6, с. 74]. Важные нюансы этой интерпретации легендарного образа отмечает и современный исследователь К.А. Чекалов в единственной на сегодняшний день русскоязычной работе, посвященной творчеству Бероальда де Вервиля: «В облике Жанны сочетаются черты традиционной романической амазонки и умудренной в вопросах любви светской дамы» [І2, с. I50]. Соединение героического и куртуазного наполнения в версии Бероальда де Вервиля определялось влиянием культуры Возрождения и было унаследовано следующим столетием. В целом, можно заключить, что к середине XVII в. смысловой ореол образа Жанны д’Арк основывался на соединении трех важнейших идей: героического служения Франции, божественного чуда, явленного в ее деяниях, и галантной любви. В орлеанском эпизоде мемуаров Мадемуазель важными являются два первых значения, а любовный сюжет, сквозной для общей повествовательной канвы, выполняет вспомогательную функцию. 
Во второй половине XVII в. образ Жанны д’Арк стал частью более широкого феномена социального и историко-культурного плана, определяемого исследователями как герочческий феминизм. Он был связан с новым представлением о роли женщины в обществе, сформировавшимся в эпоху Возрождения, но уходящим корнями в Античность, прежде всего к образу Афины Паллады, богини-воительницы и покровительницы искусств. Итальянские гуманисты, ориентируясь на античное наследие, закрепили в культуре новый идеал женщины, способной влиять на общественно-политическую и культурную жизнь, проявляя при этом выдающиеся и даже героические качества. Речь шла о дамах знатного происхождения, имена которых сохранили историки и поэты. В числе таковых Мантуанская маркиза Изабелла д’Эсте, покровительница Л. Ариосто, воспетая им в поэме «Неистовый Орландо» (Песнь XIII, строфа 59) [3, с. 226], герцогиня Урбинская Елизавета Гонзаго, восхищение которой выразил Б. Кастильоне в трактате «Придворный» [6, с. I83], и другие знаменитые итальянки ${ }^{2}$. Во Франции галерею «сильных женщин» («femmes fortes»)3 возглавили славные представительницы королевской династии, такие как Маргарита Наваррская, Маргарита Савойская, Маргарита де Валуа.

Их судьбы стали частью истории королевской династии, о которой Мадемуазель была прекрасно осведомлена. Что же касается литературных источников, то достоверных сведений о круге ее чтения очень мало, поэтому можно только предполагать, с какими именно произведениями она была знакома. Известно, что развитие индивидуальности герцогини происходило не без влияния (хотя и незначительного) атмосферы Люксембургского дворца, в котором ее отец Гастон Орлеанский вращался в кругу гуманистов и покровительствовал им. В гораздо большей степени ее ценности и вкусы были сформированы салоном маркизы де Рамбуйе, прославлявшим «культ рыцарского идеала и благородных подвигов» [І3, с. 2І2], а значит, она в той

\footnotetext{
I Этот термин мы выделяем курсивом, учитывая его современный характер и слабую степень отрефлексированности в отечественном литературоведении. Основной работой на эту тему считается монография Я. Маклина [17].

2 Перечень имен дает Я. Буркхардт [5, с. 264].

3 Это закрепившееся в истории культуры определение используется в названии книги французского иезуита и сочинителя отца Лемуана «Галерея сильных женщин» (Le Moyne P., “La Galerie des Femmes Fortes”), опубликованной в I647 г. и имевшей широкое распространение в аристократических салонах.
} 
или иной мере была знакома с наиболее популярными в Голубой комнате сочинениями. Думается, справедливо вести речь именно о знакомстве, а не о чтении, так как, по признанию Мадемуазель, она полюбила читать, только оказавшись в изгнании [I8, I, с. 297] $]^{4}$, и тогда же, напомним, приступила к созданию мемуаров. Важно подчеркнуть, что ее идеалы подпитывались не столько конкретными произведениями, но общей культурной атмосферой придворной и салонной жизни.

К середине XVII в. среди знатных дам имели большую популярность сочинения, восхвалявшие выдающихся женщин, будь то поэмы итальянских гуманистов (Боярдо, Ариосто, Тассо) или же произведения современников, посвященные самым достойным из здравствующих представительниц прекрасного пола. Чаще всего их адресатами становились королева-мать Анна Австрийская или Мадемуазель де Монпансье. Из всего выше сказанного следует, что образ «femme forte» был важной составляющей той среды, в которой сформировалась личность принцессы. Более того, «течение героического феминизма, которое питает театр и роман с начала семнадцатого века и достигает своей кульминации в эпоху Фронды, обнаруживает в лице Мадемуазель одну из наиболее постоянных и значимых иллюстраций. Оно даже позволяет увидеть в ней в І640-I655 гг. одну из живых моделей» [15, c. 6o] 5 . Подтверждением этого тезиса служат ее мемуары, в особенности эпизод, связанный с событиями в Орлеане весной г652 г.

Они имели место в разгар Фронды принцев, когда Мадемуазель 25 марта отправилась в этот важный в стратегическом отношении город для предотвращения его перехода в руки сторонников Мазарини. Она встала на сторону фрондеров, потому что видела свою задачу в укреплении союза Людовика XIV с принцами крови и спасении отечества от власти иноземного кардинала, который «думает только о своих интересах и нисколько не заботится ни о короле, ни о государстве» [І8, I, с. I86]. В орлеанском эпизоде Мадемуазель изобразила себя своего рода новой амазонкой, которая скачет верхом навстречу опасности, дает смотр войскам, принимает участие в военных советах. Протагонистка предстала в героическом ключе,

\footnotetext{
4 Здесь и далее текст цитируется в нашем переводе с указанием номера тома и страницы [18].

5 Жан Гарапон рассматривает посвященные Мадемуазель и другим знатным дамам сочинения, создающие образ "femme forte" [15, с. 77-90].
} 
что позволяет предполагать ориентацию автора на литературные образы женщин-воительниц, в частности на «Неистового Орландо» Ариосто (Брадаманта) и «Освобожденный Иерусалим» Тассо (Клоринда, Армида и др.). Подчеркнем, что, находясь в изгнании, Мадемуазель специально начала изучать итальянский язык, «чтобы читать Тассо» [I8, I, с. 44I], следовательно, достаточно хорошо знала эту поэму. Образы знатных принцесс, отважных в бою, добродетельных, верных отечеству и ведомых Провидением, соответствовали представлению мемуаристки о той высокой миссии, которая была предначертана ей как представительнице королевского дома Бурбонов.

Мадемуазель отправилась в Орлеан для того, чтобы личным присутствием поддержать права своего отца как законного владельца Орлеанского апанажа. Фрондеры рассчитывали на личное присутствие Месье, однако он предпочел переложить эти обязанности на плечи дочери. Судьбоносный характер предстоящей поездки акцентируют детали, имеющие трансцендентный смысл. Среди таковых - астрологическое предсказание маркиза де Вилена, полученное протагонисткой в день отъезда из Парижа и отмеченное в ее записной книжке: «Все, что вы предпримите с полудня среды 27 марта до пятницы, будет иметь успех, и также в это время вы совершите необыкновенные поступки» [І8, I, с. І8г]. Важность этого предсказания подчеркивает аналепсис. Оно фиксируется в повествовании с нарушением хронологии: не в момент произнесения, а в виде воспоминания, посетившего Мадемуазель накануне «штурма» города. Как пишет В.Д. Алташина, «это более естественно, чем, если бы она поместила этот факт на своем месте, не связав его с теми событиями, которые, действительно, произошли в этот знаменательный день» [2, с. I94]. Кроме того, аналепсис усиливает элемент чудесного в автобиографическом повествовании. Мемуаристка сообщает, что изначально не очень поверила в предсказание, а оказавшись у стен города, не увидела объективных предпосылок для его осуществления. Тем не менее предсказание сбылось, словно действиями протагонистки руководил кто-то свыше. Мадемуазель, в сознании которой сакральное и профанное чудо нередко смешивались, трактует этот астрологический знак как знамение небесное и в результате предстает еще одной спасительницей Орлеана, посланной, подобно Жанне д’Арк, самим Провидением.

Его волю она ощущала и подспудно, в полном соответствии с укорененным в сознании французских монархов представлением о том, что 
Божественный глас достигает государей прежде, чем обычных людей. Предстоящее славное свершение дочь Гастона Орлеанского предчувствовала заранее и за сутки до принятия отцом решения о ее миссии сказала своему секретарю: «Держу пари, что в Орлеан поеду я» [I8, I, с. I74]. Свое восшествие в город она представляет как необыкновенный поступок (chose extraordinaire), как первое славное свершение в ее необыкновенной судьбе (fortune extraordinaire), соответствовавшее статусу принцессы крови. Во второй половине XVII в. этим словом обозначали «то, что происходит не каждый день, то, что случается редко» [I4, с. 816]. Согласимся с Ж. Гарапоном, который считает употребление этого эпитета данью романической традиции и вместе с тем указывает, что категория «extraordinaire» «не сводится к сверхъестественному, но походит на чудо» [15, c. I43]. Действия Мадемуазель в Орлеане изображаются как необыкновенные, т. е. выходящие за границы обыденного и имеющие трансцендентное измерение. Не случайно она молится в церкви перед началом орлеанской миссии и жаждет божественного благословения. Хотя указания на религиозность Мадемуазель присутствуют на протяжении всего повествования, в этом эпизоде они приобретают особую значимость в связи с ее восприятием и реконструкцией происходящего.

Возвышенно-героический ореол вокруг образа протагонистки создают разнообразные детали. Бесчисленное число людей благословляло ее отъезд на улицах Парижа, а вскоре встреченный эскорт из пятисот всадников поприветствовал принцессу и начал ее сопровождать. В окружении доблестных военных она вышла из кареты и села верхом: «<..> это подарило войскам огромную радость меня видеть». И далее: «С этого момента я начала отдавать приказы <...> [І8, I, с. I77]. Восторг простых солдат разделяли и офицеры, которые радовались прибытию Мадемуазель к воротам Орлеана, «даже больше, чем если бы это был Месье» [18, I, с. I78]. Ее появление у стен города вполне отвечало возвышенным строкам Л. Ариосто, хотя и посвященным другой воительнице: «Громка ее удаль, громче того красота, / Имя ее знаменито: / Это Брадаманта...» (Песнь I, строфа 70) [3, с. 34]. Оказавшись в непривычной для себя обстановке, Мадемуазель быстро освоилась, начала отдавать приказы и сумела себя поставить. Она была полна решимости оказаться в Орлеане и, невзирая на советы приближенных, неукоснительно шла к достижению поставленной цели. Твердость ее намерений демонстрируют 
слова, обращенные к герцогу де Рогану: «Что касается меня, то нечего и обсуждать, я войду прямо в Орлеан. Если сначала они не пустят меня в ворота, я не отступлюсь, возможно, упорство их одолеет. Если я войду в город, мое присутствие укрепит дух тех, кто расположен служить его королевскому высочеству, оно вернет тех, кто не расположен. Ибо, когда видят людей моего достоинства, подвергающих себя риску, это очень воодушевляет народ <...>. Если клика мазаринистов сильнее, я буду держаться против них так, как смогу; если же, наконец, они заставят меня покинуть город, я направлюсь в армию <...>. В худшем случае, они меня арестуют» [18, I, с. I8о]. Нетерпение и решительность Мадемуазель предстают столь же сильными, как желание Брадаманты, не медля, сразиться с неузнанным ею Руджьером: «Так прекрасная воительница / Ждет трубы, рвется в бой, / И как будто в жилах не кровь, а пламя» (Песнь XLV, строфа 7I) [4, с. 7I].

Видя трусость градоначальников, герцогиня сделала ставку на народ, приветствовавший ее с городских укреплений криками «Да здравствует король, принцы! Нет Мазарини!» В ответ на этот популярный в период Фронды клич она дерзко подстрекала жителей города встать на свою сторону: «Идите в мэрию и заставьте открыть мне ворота!» [I8, I, с. I8I]. Ее смелый призыв подчеркивал стремление вести других за собой, подобно тому, как это делала тассовская Клоринда: «Друзья, - кричит она, - теперь за наши / Права вступились сами Небеса; / > ..> Вперед! Вперед! За мной, друзья, куда / Судьба нам путь указывает славный!» (Песнь VII, строфа II7) [Іо, с. 240]. В духе средневековой идеи о союзе знати и народа как основы блага Франции Мадемуазель демонстрировала свою готовность вершить великие дела.

Сама идея единения принцессы с народом, который поддерживает ее во имя справедливого дела и превращает в настоящую героиню, отсылает и к современному Мадемуазель литературному контексту, в частности к трагедии П. Корнеля «Никомед» (165I). Мадемуазель имела его сочинения в своей библиотеке и была почитательницей творчества драматурга, чье влияние ощущается в тексте мемуаров на уровне построения сцен и образов, а также лексики. «Ключевые слова корнелевского словаря и моральные категории, которые из них вытекают, проникают в повествование с начала I652 г. и оставляют на нем глубокий отпечаток: “великие дела”, “долг”, “склонность”, “неприязнь”, “решение” [I5, с. I50-I5I]. Сюжет трагедии «Никомед», как известно, соотносился поколением мемуаристки с событи- 
ями Фронды, а образ главного героя вызывал ассоциации с принцем Конде. Но для понимания интенций мемуаристки важнее не прямые параллели, а сама идея служения благородному делу. В трагедии «Никомед» поддержку народа несправедливо преследуемому принцу обеспечила его невеста Лаодика, чей образ соответствовал идеалу герочческого феминизма. В диалоге с Арсиноей она оправдывала свои действия высшей необходимостью: «А я царица. Мне, чтоб одолеть вас в споре, / Был нужен их мятеж, и вот он, вам на горе!» (Действие V, явление 6) [7, с. 46o]. Мадемуазель не воспринимала свои действия как мятежные, но образ армянской царицы, верной принцу Никомеду и апеллирующей к народу, мог стать одной из составляющих той героической матрицы, которая легла в основу ее автобиографического творчества. Добавим, что верность принцу Конде стимулировала упорное стремление герцогини сохранить влияние в Орлеане и также соответствовала модели поведения корнелевских героев.

Рассказ о «штурме» города строится по принципу последовательной передачи событий, отличается особой динамикой, детальностью и экспрессией. Как верно замечает В.Д. Алташина, «о напоре и решительности мадемуазель говорят глаголы действия, которые она употребляет» [I, с. 95]. Мемуаристка прибегает и к выразительному сравнению, называя свои действия похожими на поведение кошки, всегда безошибочной в своих движениях: «По правде говоря, я мало думала о том, какую дорогу выбрать, ибо, не думая об этом, я взбиралась, как это делала бы кошка, цепляясь за все колючки и шипы и перепрыгивая все изгороди, не причинив себе никакого вреда» [I8, I, c. I82]. В оригинале слова «колючки / колючие кустарники» («ronces») и «шипы» («épines»), помимо прямого значения, имеют еще и важное для смыслового контекста переносное: «затруднения», «неприятности». Точно найденный образ помогает передать уверенность Мадемуазель в благополучном исходе дела и своих поступках, вновь отмеченных печатью необыкновенного. Она все же оказалась в Орлеане, невзирая на препятствия. Хотя героиня мемуаров не держала в руках оружия, но действовала смело и отчаянно, к тому же вдохновляла других. Ее моральный дух, выраженный в слове, по силе своего воздействия сравним с мечом Армиды и ее отношением к своему предназначению: «Я - женщина, но родилась в венце; / Руке ж, которой подобает скипетр / Властительный держать, равно приличен / И бранный меч <...> (Песнь XVII, строфа 43) [Іо, с. 484]. Поведение Мадемуазель было 
продиктовано аристократической ментальностью, основанной на идее риска и игры с опасностью. Дерзкое величие ее восшествия в Орлеан подчеркивает деталь, связанная с названием городских ворот. «Взбучка» - так они стали именоваться в честь принцессы, преодолевшей их вопреки и в назидание противникам. В самом городе этот героический демарш, который Мадемуазель назвала словом «триумф» [I8, I, с. I83], был встречен криками толпы и боем барабанов. Протагонистка находилась в состоянии душевного подъема, переходящего в эйфорию, и от радости была «вне себя» [І8, I, с. I83].

Ее пребывание в Орлеане передается с использованием лексики, создающей образ полноправной властительницы: она «командовала в городе» [І8, I, с. І84], «приказывала то, что хотела» [І8, I, с. г95], «действовала с абсолютной властью» [І8, I, с. I85]. Эти формулировки находят подтверждение на содержательном уровне. Мадемуазель распорядилась вернуть крестьянам украденный у них скот, убедила членов муниципалитета открыть принцу Конде доступ в город, определила направление движения армии и т. д. Она дорожила своим авторитетом, поэтому отказалась от письменного свидетельства отца на право распоряжаться в городе, считая собственное происхождение самым весомым аргументом в пользу своей власти. Будучи полновластной хозяйкой в Орлеане, герцогиня тем не менее воспринимала свое могущество как дань служения королю. Об этом свидетельствует ее реакция на просьбу горожан воспользоваться для собственных нужд денежными средствами, собранными в качестве королевского налога. «Я не просто была рассержена, а даже испытала отвращение от этого предложения» [I8, I, с. І93], - пишет Мадемуазель, четко выражая свое представление о социальной иерархии и этике французской знати.

Мемуаристка стремится придать большую весомость орлеанскому эпизоду, подкрепляя свое повествование оценками других людей, зафиксированными документально. Она цитирует письма Гастона Орлеанского и принца Конде, в которых первый называет ее поступок достойным внучки Генриха Великого [I8, I, с. I92], а второй приписывает ему высшую значимость [ı8, I, с. І94]. Однако, по мнению историков, прибытие Мадемуазель в Орлеан не сыграло заметной роли в ходе гражданской войны. Важным, поистине героическим этот эпизод стал только для самой принцессы, превратившись в своеобразную мерку для сравнения со всеми последующими событиями Фронды. 
Особое отношение мемуаристки к воспоминаниям об Орлеане объясняется, как минимум, тремя причинами. Прежде всего, первой по времени возможностью проявить себя в героическом духе, присущем представителям королевского рода. Во-вторых, обращением к истории главного города Орлеанского герцогства, защита которого подтвердила силу знатных родов как единственной опоры монарха. В-третьих, связью Орлеана с именем Жанны д’Арк. Сравнение Мадемуазель с Девой в мемуарах присутствует. Оно вкладывается в уста Английской королевы и передается как косвенная речь. Мемуаристка вводит эту параллель осторожно, намеренно ее не акцентируя, однако даже беглой отсылки к Жанне д’Арк оказывается достаточно, чтобы возвысить образ протагонистки и усилить его героическое наполнение.

Орлеанский эпизод мемуаров показывает, что мечта Мадемуазель о высоком и необычайном подпитывалась историческими и литературными источниками, связанными с идеалом героического феминизма. Они помогли мемуаристке описать свое восшествие в город как важный момент Фронды и превратить объективно незначительный исторический факт в яркий, показательный, поистине триумфальный эпизод своей биографии. Культурная атмосфера, насыщенная примерами возвышенно-героических поступков необыкновенных женщин, повлияла на конструирование автобиографического образа. Мадемуазель показала себя отважной принцессой, достойной славы Бурбонов, ведомой Провидением и поддерживаемой народом, что отразило ее представление о своем высоком предназначении. 


\section{Список литературы}

I $\quad$ Алташина В.Д. Поэзия и правда мемуаров (Франция, XVII-XVIII вв.).

СПб.: Изд-во ГРПУ им. А.И. Герцена, 2005. 173 с.

Алташина В.Д. Роман-мемуары во французской литературе XVIII века: генезис и поэтика: дис. ... д-ра филол. наук. СПб., 2007. 546 с.

Ариосто Л. Неистовый Роланд. Песни I-XV. М.: Литературные памятники, I993. $574 \mathrm{c}$.

Ариосто Л. Неистовый Роланд. Песни XVI-XLVI. М.: Литературные памятники, I993. $544 \mathrm{C}$.

Буркхардт Я. Культура Италии в эпоху Возрождения. М.: Интрада, 200I. 543 с.

6 Кастильоне Б. О Придворном // Сочинения великих итальянцев XVI в. СПб.: Алетейя, 2002. С. І8I-247.

7 Корнель П. Театр: в 2 т. М.: Искусство, І984. Т. 2. 688 с.

8 Макарова А.Л. Культурный контекст оперы Чайковского «Орлеанская дева» // Известия Уральского федерального университета. Серия 2: Гуманитарные науки. 20I4. T. I27, № 2. С. I87-I99.

9 Некрасова И.А. Жанна д’Арк - героиня французской религиозной трагедии // Вопросы театра / Proscaenium. 20IO. № I-2. C. 297-307.

IO Tacco T. Освобожденный Иерусалим. СПб.: Наука, 2007. 7I5 c.

II Tогоева О.И. Формирование культа святой Жанны д’Арк и политическая культура Франции (XV-XIX вв.): автореф. дис. ... д-ра истор. наук. М., 20I3. 38 с. Чекалов К.А. Маньеризм во французской и итальянской литературах. М.: Наследие, 200I. 208 с.

I3 Craveri B. Làge de la conversation. Paris: Gallimard, 2002. 680 p.

I4 Furetière A. Dictionnaire universel, contenant généralement tous les mots françois tant vieux que modernes, et les termes de toutes les sciences et des arts. Rotterdam-La Haye: A. et R. Leers, I690. 2160 p.

I5 Garapon J. La culture d'une princesse. Ecriture et autoportrait dans l'œuvre de la Grande Mademoiselle (1627-I693). Paris: Honoré Champion éd., 2003. 444 p.

I6 Lanéry d'Arc P. Le Livre d'or de Jeanne d'Arc, bibliographie raisonnée et analytique des ouvrages relatifs à Jeanne d'Arc, catalogue méthodique, descriptif et critique des principales études historiques, littéraires et artistiques, consacrées à la Pucelle d’Orléans, depuis le XVe siècle jusqu'à nos jours. Paris: H. Leclerc et Cornuau, I894. IO42 p.

I7 MacLean I. Woman Triumphant: Feminism in French Literature, I6IO-I652. Oxford: Clarendon Press, I977. $314 \mathrm{p}$.

I8 Mademoiselle de Montpensier. Mémoires: en 2 t. Paris: Librairie Fontaine éd., I985. $490 \mathrm{p} .+454 \mathrm{p}$. 


\section{References}

Altashina V.D. Poeziia i pravda memuarov (Frantsiia, XVII-XVIII vv.) [Poetry and truth of memoirs (France, $I 7^{\text {th }}-I 8^{\text {th }}$ centuries)]. St. Petersburg, Izd-vo GRPU im. A.I. Gertsena Publ., 2005. I73 p. (In Russ.)

Altashina V.D. Roman-memuary vo frantsuzskoi literature XVIII veka: genezis i poetika: diss... d. filol. $n$. [Memoir novel in the $18^{\text {th }}$-century French Literature: genesis and poetics. DSc diss.]. St. Petersburg, 2007. 546 p. (In Russ.)

Ariosto L. Neistovyi Roland. Pesni I-XV [Orlando Furioso]. Moscow, Literaturnye pamiatniki Publ., I993. 574 p. (In Russ.)

Ariosto L. Neistovyi Roland. Pesni XVI-XLVI [Orlando Furioso]. Moscow, Literaturnye pamiatniki Publ, I993. 544 p. (In Russ.)

Burkkhardt Ia. Kul'tura Italii v epokhu Vozrozhdeniia [Italian Renaissance Culture]. Moscow, Intrada Publ., 200I. 543 p. (In Russ.)

Kastil'one B. O Pridvornom [Baldassare Castiglione. The Book of the Courtier]. Sochineniia velikikh ital'iantsev XVI $v$. [Works by Great Italians. $6^{\text {th }}$ centure]. St. Petersburg, Aleteiia Publ., 2002, pp. I8I-247. (In Russ.)

Kornel' P. Teatr: $v 2$ t. [Plays: in 2 vol.]. Moscow, Iskusstvo Publ., I984. Vol. 2. 688 p. (In Russ.)

Makarova A.L. Kul'turnyi kontekst opery Chaikovskogo "Orleanskaia deva” [Cultural Context of Tchaikovsky's opera The Maid of the Orleans]. Izvestiia Ural'skogo federal'nogo universiteta. Seriia 2: Gumanitarnye nauki [Series 2. Humanities], 20I4, vol. I27, no 2, pp. I87-I99. (In Russ.)

Nekrasova I.A. Zhanna d'Ark - geroinia frantsuzskoi religioznoi tragedii [Jeanne d'Arc - the heroine of French religious tragedy]. Voprosy teatra / Proscaenium, 20I0, no I-2, pp. 297-307. (In Russ.)

Tasso T. Osvobozhdennyi Ierusalim [Jerusalem Delivered]. St. Petersburg, Nauka Publ., 2007. 715 p. (In Russ.)

Togoeva O.I. Formirovanie kul'ta sviatoi Zhanny d'Ark i politicheskaia kul'tura Frantsii $(X V-X I X v v$.): avtoref. diss. ... d. ist. $n$. [The rise of Jeanne d'Arc cult and Political Culture in France of the $15^{\text {th }}-16^{\text {th }}$ centuries: Author. DSc diss. Abstract]. Moscow, 20I3. 38 p. (In Russ.)

Chekalov K.A. Man'erizm vo frantsuzskoi i ital'ianskoi literaturakh [Mannerism in French and Italian literature]. Moscow, Nasledie Publ., 200I. 208 p. (In Russ.) Craveri B. L'àge de la conversation. Paris, Gallimard, 2002. 680 p. (In French) Furetière A. Dictionnaire universel, contenant généralement tous les mots françois tant vieux que modernes, et les termes de toutes les sciences et des arts. Rotterdam-La Haye, A. et R. Leers, I690. 2160 p. (In French) Garapon J. La culture d'une princesse. Ecriture et autoportrait dans l'œuvre de la Grande Mademoiselle (I627-I693). Paris, Honoré Champion éd., 2003. 444 p. (In French) 
I6 Lanéry d'Arc, Pierre. Le Livre d'or de Jeanne d'Arc, bibliographie raisonnée et analytique des ouvrages relatifs à Jeanne d'Arc, catalogue méthodique, descriptif et critique des principales études historiques, littéraires et artistiques, consacrées à la Pucelle d'Orléans, depuis le XVe siècle jusqu'à nos jours. Paris, H. Leclerc et Cornuau, I894. I042 p. (In French)

I7 MacLean I. Woman Triumphant: Feminism in French Literature, I6IO-I652. Oxford, Clarendon Press, I977. 3I4 p. (In English)

I8 Mademoiselle de Montpensier. Mémoires: en 2 t. Paris, Librairie Fontaine éd., I985. 490 p. + 454 p. (In French) 